\title{
LOW TEMPERATURE BAINITE
}

\author{
C. Garcia-Mateo, F. G. Caballero ${ }^{\dagger}$ and H. K. D. H. Bhadeshia \\ University of Cambridge \\ Department of Materials Science and Metallurgy \\ Pembroke Street, Cambridge CB2 3QZ, U.K. \\ $\nmid$ Centro Nacional de Invesigaciones Metalurgicas (CENIM) \\ Consejo Superior de Investiaciones Cientificas (CSIC) \\ Avda. Gregorio del Amo, 8, 28040 Madrid, Spain
}

Journal de Physique IV, Vol. 112 (2003) 285-288. 


\begin{abstract}
It is demonstrated that bainite can be obtained by isothermal transformation at a temperature which is so low that the calculated diffusion distance of an iron atom, over the time scale of the experiment, is many orders of magnitude less than an interatomic spacing; and yet, it is possible to obtain plates of bainite which are a few micrometers in length. Bainite has been obtained by isothermal transformation at $400 \mathrm{~K}$. The time taken for nucleation at this temperature can be many days, but the transformation results in the growth of extremely thin platelets of bainite, so thin that the hardness of the resulting steel can be greater than $600 \mathrm{HV}$.
\end{abstract}

\title{
1. INTRODUCTION
}

Bainite is expected below the $T_{0}^{\prime}$ temperature when:

$$
\Delta G^{\gamma \rightarrow \alpha}<-G_{S B} \quad \text { and } \quad \Delta G_{m}<G_{N}
$$

where $G_{S B} \simeq 400 \mathrm{~J} \mathrm{~mol}^{-1}$ is the stored energy of bainite $(\alpha)[1] ; \Delta G^{\gamma \rightarrow \alpha}$ is the free energy change accompanying the transformation of austenite $(\gamma)$ without any change in chemical composition. The first condition therefore describes the limits to growth. The second condition refers to nucleation; thus, $\Delta G_{m}$ is the maximum molar Gibbs free energy change accompanying the nucleation of bainite [2]. $G_{N}$ is a universal nucleation function based on a dislocation mechanism of the kind associated with martensite [1-3]. The temperature dependence of $G_{N}$ is, for low-alloy steels, independent of chemical composition; together with the growth condition, the function allows the calculation of the bainite-start temperature from a knowledge of thermodynamics alone $[1,2]$. The $T_{0}^{\prime}$ temperature is that below which it is possible for austenite to transform to ferrite of the same chemical composition after allowing for the strain energy due to the displacements associated with the transformation.

In a similar scheme, martensitic transformation becomes possible when

$$
\Delta G^{\gamma \rightarrow \alpha}\left\{M_{S}\right\}<G_{N}^{\alpha^{\prime}}
$$

where the right hand side of this equation refers to the critical value of $\Delta G^{\gamma \rightarrow \alpha}$ needed to stimulate martensite by an athermal, diffusionless nucleation and growth mechanism [3].

It is possible, using equations (1) and (2) to calculate the bainite-start $\left(B_{S}\right)$ and martensitestart $\left(M_{S}\right)$ temperatures as a function of steel composition. A set of these calculations for a steel 
with sufficient hardenability to avoid other transformations are illustrated in Fig. 1a. From a thermodynamic point of view, it clearly is possible to obtain bainite at very low temperatures. To estimate whether this is a reasonable statement from a kinetic point of view, time-temperaturetransformation (TTT) diagrams were calculated as described elsewhere [5]. The time required to initiate transformation just below $B_{S}$ is plotted in Fig. 1b as a function of the carbon concentration; it takes approximately a year to begin forming bainite when the carbon concentration of the $\mathrm{Fe}-$ $3 \mathrm{Mn}-2 \mathrm{Si}$ alloy reaches $1 \mathrm{wt} \%$, and at somewhat higher concentrations reaches 10 years. Therefore, there is a severe kinetic limitation to producing bainite in such a steel for temperatures below about $400 \mathrm{~K}$. It was our aim to produce bainite at a low temperature in a steel designed for a specific structural application.
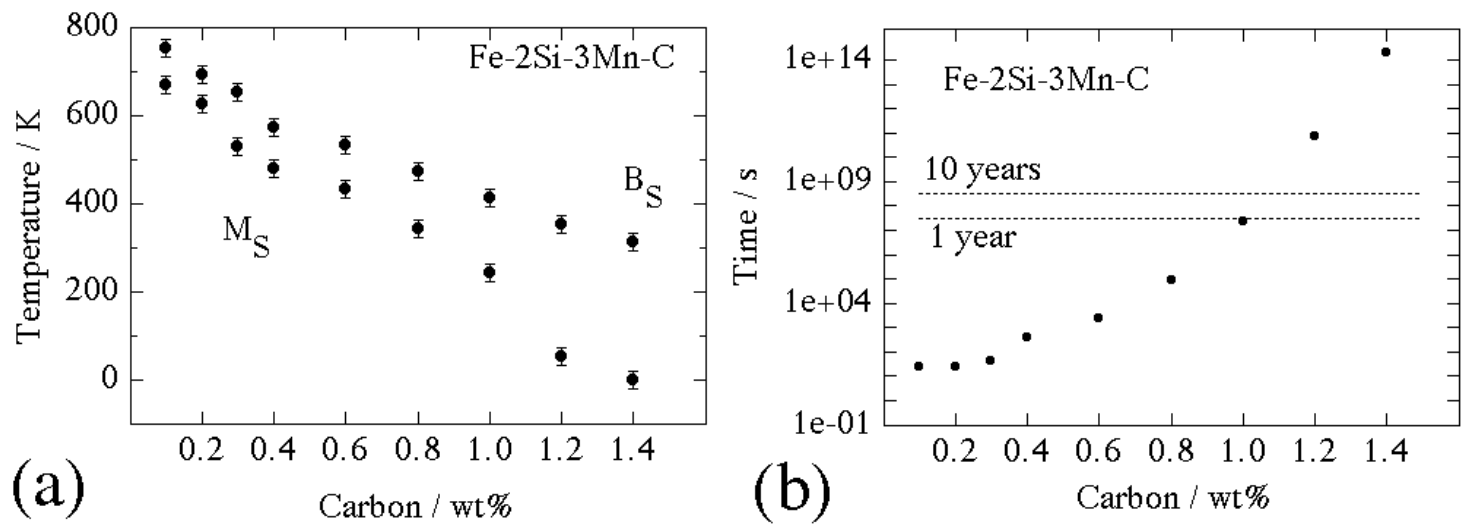

Fig. 1: Calculated transformation temperatures [1,4] and times [5] to initiate transformation at $B_{S}$ as a function of the carbon concentration.

\section{NEW ALLOY \& EXPERIMENTAL RESULTS}

The chemical composition of the alloy, measured after homogenisation at $1200{ }^{\circ} \mathrm{C}$ for 2 days whilst sealed in a quartz capsule containing pure argon, is given in Table 1. This procedure of protecting samples against oxidation was used for all heat treatments, including austenitisation at $1000{ }^{\circ} \mathrm{C}$ for 15 min prior to isothermal transformation. The martensite-start temperature was determined experimentally on a $2 \mathrm{~mm}$ diameter rod using high-speed dilatometry.

Table 1: Chemical composition, martensite-start temperature, \& measured time (days) required for the bainite reaction to stop.

\begin{tabular}{|ccccccc|c|}
\hline $\mathrm{C}$ & $\mathrm{Si}$ & $\mathrm{Mn}$ & $\mathrm{Mo}$ & $\mathrm{Cr}$ & $\mathrm{V}$ & $\mathrm{P}$ wt\% & $M_{S} /{ }^{\circ} \mathrm{C}$ \\
0.98 & 1.46 & 1.89 & 0.26 & 1.26 & 0.09 & $<0.002$ & 120 \\
\hline & $125^{\circ} \mathrm{C}$ & $150^{\circ} \mathrm{C}$ & $200^{\circ} \mathrm{C}$ & $250^{\circ} \mathrm{C}$ & $300^{\circ} \mathrm{C}$ & $325^{\circ} \mathrm{C}$ & \\
& $>60$ days & $>30$ days & 9 days & $3-4$ days & $1-2$ days & $1-2$ days & \\
\hline
\end{tabular}

The alloy contains manganese and chromium for hardenability, vanadium for austenite grain size control, silicon to prevent the precipitation of cementite during upper bainite formation and molybdenum to prevent temper embrittlement due to phosphorus. The carbon concentration was selected using calculations of the type illustrated in Fig. 1, to suppress $B_{S}$ whilst at the same time have realistic transformation times (Table 1 ). Note that only minute quantities of bainite were observed after prolonged transformation at 125 and $150{ }^{\circ} \mathrm{C}$ (Table 1 ). 
The calculated transformation temperatures and TTT diagram are shown in Fig. 2a, which also contains experimental data for the time taken to initiate and cease transformation. The measured values for the achievement of a detectable degree of transformation are in reasonable agreement with those calculated (Fig. 2a), except at the highest temperature where the time period required is underestimated.
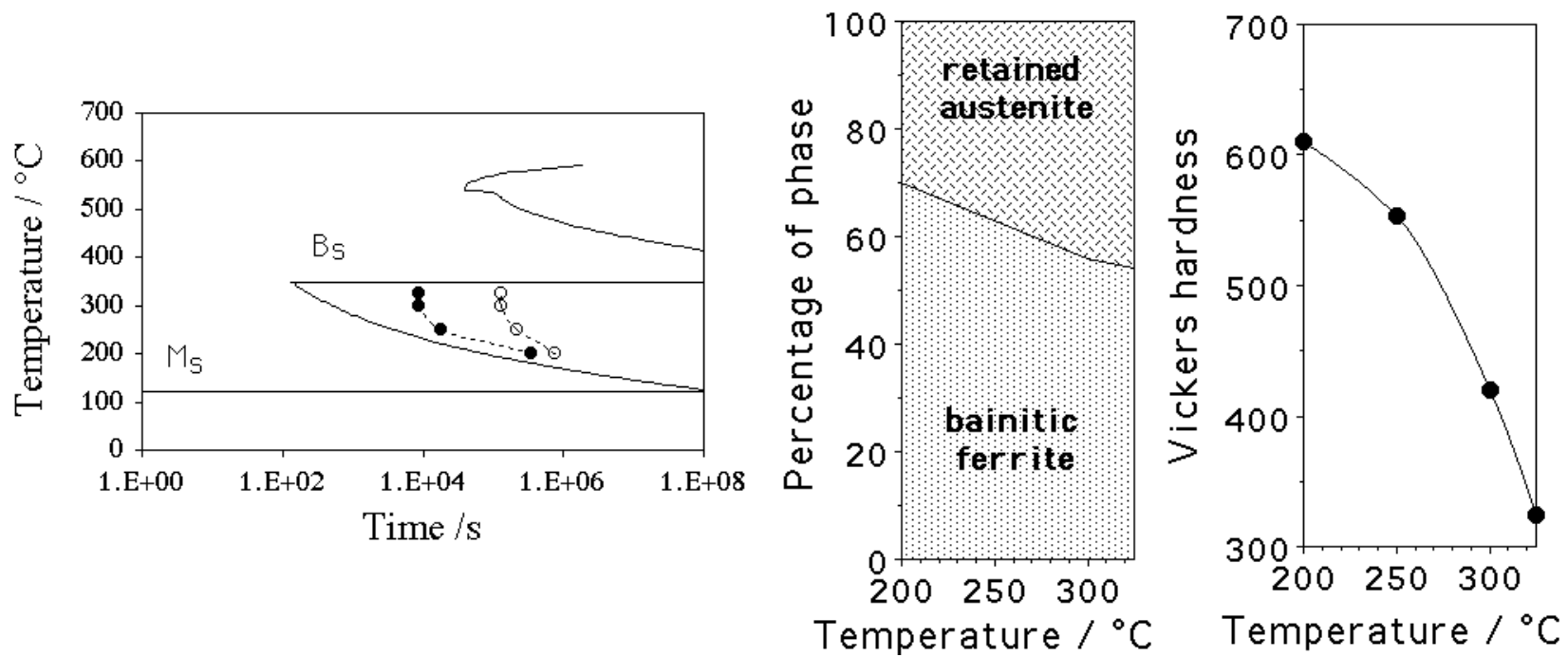

Fig. 2: (a) Calculated TTT diagram for the initiation of isothermal reaction. The filled points represent the measured start of the bainite reaction and the open circles where the reaction stops. (b) Measured phase fractions following cessation of isothermal transformation. (c) Measured hardness.

As is well known [2], the presence of silicon prevents the complete transformation of austenite because the reaction to bainite stops when the chemical composition of the austenite violates the growth condition described in equation (1). Thus, the completion of transformation leaves carbon-enriched residual austenite which can no longer transform into bainite. Fig. $2 \mathrm{~b}$ also shows the results of detailed $\mathrm{X}$-ray analysis carried out using a diffractometer with a $2 \theta$ scan rate of $1^{\circ} \mathrm{min}^{-1}$ and unfiltered $\mathrm{Cu} K_{\alpha}$ radiation. It is evident that large quantities of austenite remain untransformed; furthermore, the austenite is sufficiently enriched with carbon so that it remains stable on cooling to ambient temperature. Martensite does not form at all; in spite of this, very high hardness values are achieved (Fig. 2c), the significance of which will be discussed later. The carbon concentrations of the austenite and bainite, determined using standard X-ray analysis are presented in Fig. 3 for the samples in which the transformation had stopped.

As expected from the incomplete-reaction phenomenon [2], the carbon concentration of austenite at the point where the reaction terminates is far less than demanded by equilibrium (Ae3'), and close to that expected from the $T_{0}^{\prime}$ phase boundary after allowing for the heterogeneous distribution of carbon [2]. An interesting feature is that significant excess quantities of carbon are retained in solution within the bainitic ferrite; it is speculated that the carbon may be trapped at defects.

Selected transmission electron micrographs are presented in Fig. 4. Extensive studies proved the absence of carbides, presumably because of the high silicon concentration. The bainite plate size is found to be extremely fine, especially at the lowest transformation temperatures. Detailed sterologically corrected measurements showed a plate thickness of $32 \pm 3 \mathrm{~nm}$ for transformation at $200{ }^{\circ} \mathrm{C}$ and $49 \pm 4 \mathrm{~nm}$ for $250^{\circ} \mathrm{C}$. This is primarily what leads to hardnesses in excess of $600 \mathrm{HV}$ $[2]$. 


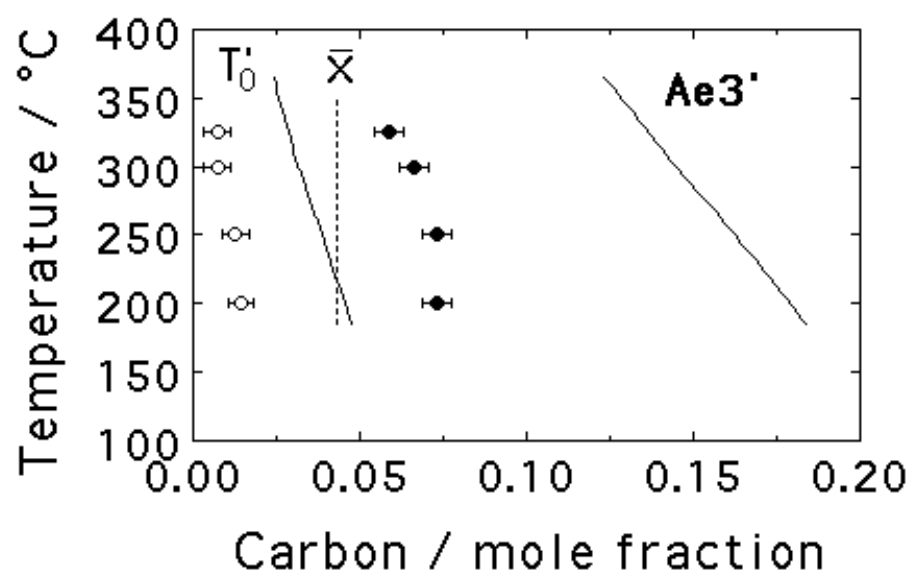

Fig. 3: Open and filled points are the measured carbon of bainite and austenite respectively.

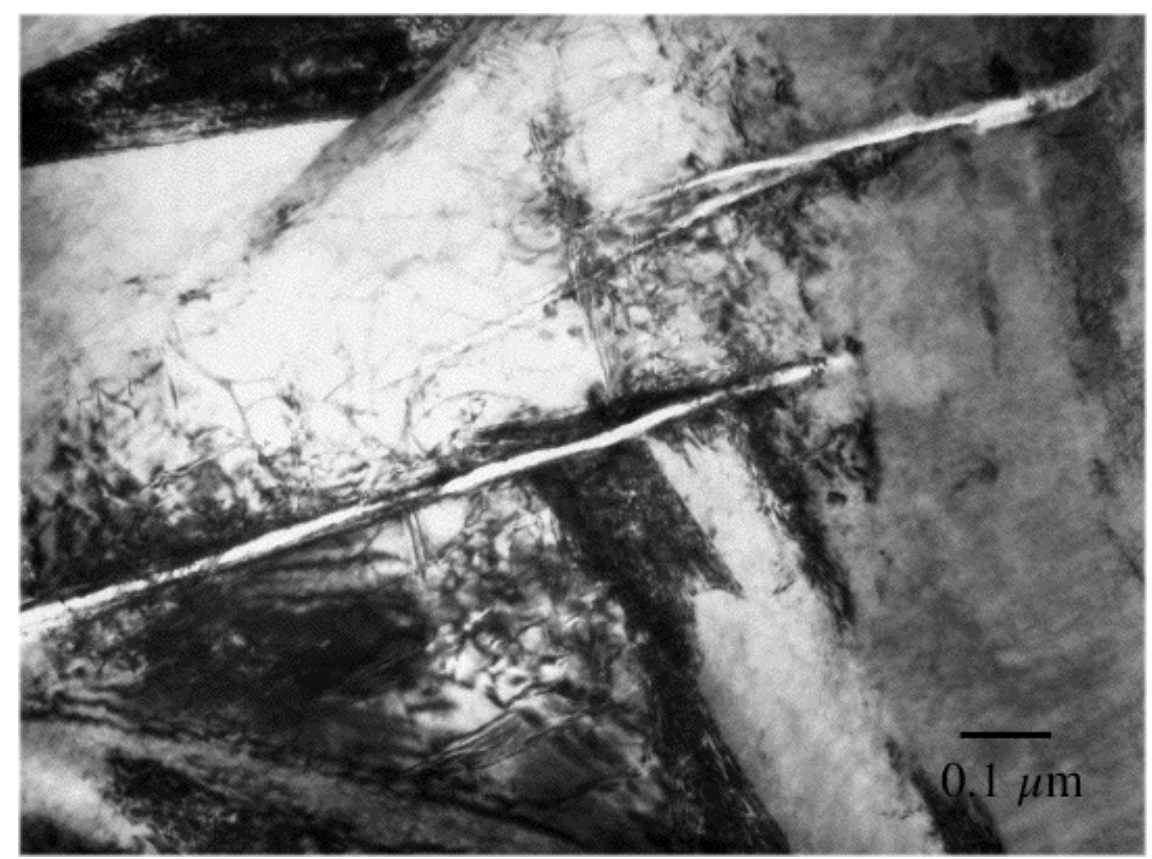

Fig. 4a: Transformed at $200^{\circ} \mathrm{C}$ for 4 days.

\section{SUMMARY}

It has been possible to achieve bainitic transformation at temperatures as low as $200-125{ }^{\circ} \mathrm{C}$, where the calculated diffusion distance of an iron atom is inconceivably small over the time period of the experiments. The transformation can only be achieved via a displacive transformation mechanism. Furthermore, the scale of the microstructure achieved is very fine indeed, amounting to tens of nanometers, an observation consistent with the very high hardness values of microstructures which are mixtures of only bainitic ferrite and carbon-enriched austenite. There are observations which remain to be explained: for example, the fact that excess carbon is retained in solid solution and that it does not precipitate during prolonged heat treatment. A possible reason for the lack of carbide precipitation is that the excess carbon in ferrite is trapped at defects, where its energy is lower than in the precipitate phase. These topics are the subject of research in progress.

We would like to acknowledge the Engineering and Physical Sciences Research Council (U.K.) for funding this work. 


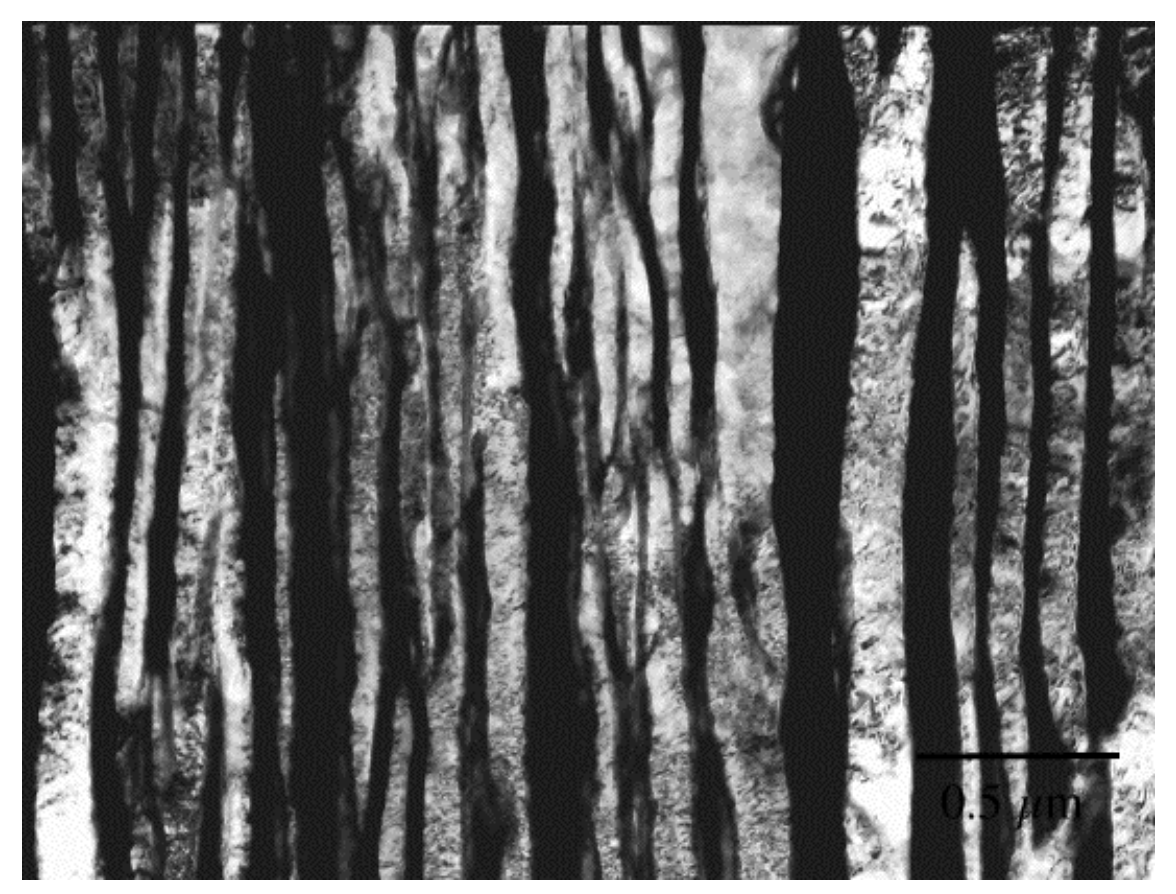

Fig. 4b: Transformed at $250^{\circ}$ for 25 days.

\section{REFERENCES}

[1] Bhadeshia, H. K. D. H., Acta Metall. 29 (1981) 1117-1130.

[2] Bhadeshia, H. K. D. H., Bainite in Steels, 2nd ed. Institute of Materials, London, 2001.

[3] Olson, G. B. and Cohen, M., Metall. Trans. 7A (1976) 1897-1923.

[4] Bhadeshia, H. K. D. H., Metal Science 15 (1981) 178-180.

[5] Bhadeshia, H. K. D. H., Metal Science 16 (1982) 159-165. 